\title{
Right extended hepatectomy for hilar cholangiocarcinoma: A case report
}

\author{
Dahal R', Adhikari KM², Pradhan $\mathrm{S}^{3}$, Bhandari $\mathrm{RS}^{4}$
}

${ }^{1}$ Romi Dahal, MCh resident; ${ }^{2}$ Krishna Mohan Adhikari, MCh resident; ${ }^{3}$ Sumita Pradhan, Assistant Professor; ${ }^{4}$ Ramesh Singh Bhandari, Professor, Department of Surgery, Tribhuvan University Teaching Hospital, Kathmandu, Nepal.

\begin{abstract}
Radical resection in a case of hilar cholangiocarcinoma is the only curative option. However resection in a hilar cholangiocarcinoma is a challenging procedure because of the low resectability rate. Only a few cases of hilar cholangiocarcinoma are operable because of the advanced nature of disease at presentation. Furthermore, the extent of surgery makes it a complicated process to attempt. We recently had a patient who underwent an open extended right hepatectomy and hepaticojejunostomy for a type Illa hilar cholangiocarcinoma.

The tumor was $20 \mathrm{~mm}$ in diameter and was located between the right hepatic duct and common hepatic duct. Radiological examination showed that the hepatic artery was not involved but the right portal vein was invaded by the tumor. CT volumetry was done and the future liver remnant was only $20 \%$ in the jaundiced patient. Preoperative drainage was done with percutaneous transhepatic biliary drainage from the left side. Portal vein embolization was done to augment future liver remnant to $30 \%$.

The patient underwent an extended right hepatectomy (right trisectionectomy combined with caudate lobectomy). The operation time was nearly $300 \mathrm{~min}$, and the intraoperative blood loss was about $500 \mathrm{ml}$. However, in the postoperative period, the patient developed post hepatic liver failure which was managed successfully with conservative treatment. The postoperative hospital stay was 23 days.

The final diagnosis was hilar cholangiocarcinoma with no nodal metastasis (pT2bN0M0) stage II (American Joint Committee on Cancer, AJCC).
\end{abstract}

Key words: Extended hepatectomy; Hilar cholangiocarcinoma; Portal vein embolization; Surgical technique.

\section{INTRODUCTION}

holangiocarcinoma is a rare disease. Of these, the majority are hilar cholangiocarcinoma (hCCA) or

\begin{tabular}{l}
\hline Access this article online \\
Website: www.jkmc.com.np \\
DOI: https://doi.org/10.3126/jkmc.v9i3.36422 \\
HOW TO CITE \\
Dahal R, Adhikari KM, Pradhan S, Bhandari RS. Right extended \\
hepatectomy for hilar cholangiocarcinoma: A case report. J \\
Kathmandu Med Coll. 2020;9(3):173-6. \\
\hline
\end{tabular}

Address for correspondence

\section{Dr. Romi Dahal}

Department of Surgery

Tribhuvan University Teaching Hospital

Kathmandu, Nepal

E-mail: srgeon1@gmail.com

Copyright $\odot 2020$ Journal of Kathmandu Medical College (JKMC)

ISSN: 2019-1785 (Print), 2091-1793 (Online)

(i) (8) This work is licensed under a Creative Commons Attribution-Non Commercial 4.0 International License. peri-hilar cholangiocarcinoma ( $\mathrm{pCCA}$ ) ranging from $60-70 \%{ }^{1}$. Complete surgical resection (R0 resection) is the only curative treatment, similar to most other malignant tumors. However, only a few cases of hilar cholangiocarcinoma are operable because of the advanced nature of the disease at presentation. Among the hilar cholangiocarcinoma, $20-50 \%$ of the cases are unresectable. Only a few (30-70\%) among the diagnosed cases of hilar cholangiocarcinoma can be resected, with improving resection rates and with more experience ${ }^{2},{ }^{3}$. These tumors are difficult to treat because of their tumor location. The close proximity to the major hepatic vessels makes it cumbersome and at times very difficult to achieve free distal margin with $\mathrm{R} 0$ resections. The proximity to the liver parenchyma in addition to the involvement of hepatic vessels often warrants the complex hepatic resections along with bile duct excision. The cholangiocarcinoma is also associated with high desmoplastic reactions and has a rich tumor microenvironment, all these characteristics contribute to its therapeutic resistance ${ }^{4}$. Preoperative optimization 
is required and liver volume augmentation is necessary to achieve curative resection in those cases where the future liver remnant (FLR) volume is insufficient.

We present a case of hCCA Type Illa in which the tumor involves the biliary confluence and extends towards the right hepatic duct. The patient had to undergo Portal Vein Embolization (PVE) due to insufficient FLR. After 3 weeks of PVE, curative (R0) resection was finally possible.

\section{CASE REPORT}

The patient is a 67-year-male who presented with complaints of anorexia for nine months and yellowish discolouration of his body for one month. He was evaluated for the symptoms which turned out to be Type Illa hilar cholangiocarcinoma. The diagnosis was made with contrast enhanced CT scan of abdomen and pelvis. The tumor was $20 \mathrm{~mm}$ in diameter and located between the right hepatic duct and common hepatic duct. Radiological examination showed that the hepatic artery was not involved but the right portal vein was invaded by the tumor. Volumetric analysis was done and the FLR was calculated to be $20 \%$. Preoperative drainage was done with PTBD from the left side by the Intervention Radiology (IR) team. The initial CT scan showed a total liver volume (TLV) to be $1546 \mathrm{cc}$ making FLR with caudate lobe: $331 / 1546=21.41 \%$ and FLR without caudate lobe: $310 / 1546=20.05 \%$.

The patient was planned for PVE as his FLR was inadequate. After PVE, repeat CT scan, was done after 3 weeks which showed a TLV of $1267 \mathrm{cc}$, segment II and III of $383 \mathrm{cc}$ with a FLR of $30 \%$. The kinetic growth rate was calculated using the formula for kinetic growth calculation to be $10 \% / 3$ weeks, i.e. $3.3 \%$ per week $(>2 \%$ per week) which was satisfactory ${ }^{5}$.

In this case the issue of inadequate FLR (20\%) was tackled with PVE, which improved FLR to $30 \%$ in 3 weeks.

Staging laparoscopy was done initially. Intraoperatively, there was no ascites, no peritoneal or other deposits suggestive of metastasis. With these findings, we proceeded with the surgery and were able to remove the tumor. During the procedure, modified Makuuchi incision was given, liver was mobilized, right hepatic vein was mobilized, right portal vein was clamped and parenchymal transaction was done. There was an intraoperative blood loss of $500 \mathrm{ml}$ and the duration of surgery was 300 minutes.

In the postoperative period, the patient developed Grade B Post Hepatic Liver Failure (PHLF) which was managed conservatively with albumin and Fresh Frozen Plasma (FFP). His bilirubin level elevated more than 18 times the normal range, with reduction in his platelets count upto 42000 per microliter of blood. He started to improve only after the $10^{\text {th }}$ postoperative day indicating the slow recovery from PHLF.

The right subhepatic drain was draining more than 500 $\mathrm{ml}$ of ascitic fluid till $14^{\text {th }}$ postoperative day, which was also managed conservatively with IV fluids, oral fluids (with ORS) and enteral nutrition. The amount of drain then decreased slowly over a period of time.

Histopathological examination showed the tumor to be a well differentiated cholangiocarcinoma, biliary type in the perihilar duct. There was no lymphovascular invasion. The resection margins were free of tumor. Hilar vessels, liver, and lymph nodes were also free of tumor (PT2aN0). However, perineural invasion was seen.

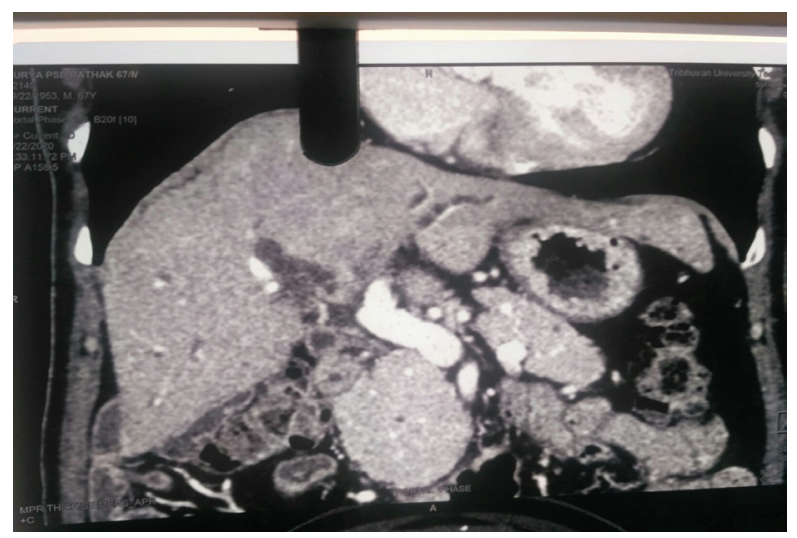

Figure 1: Preoperative CECT showing occlusion of right portal vein

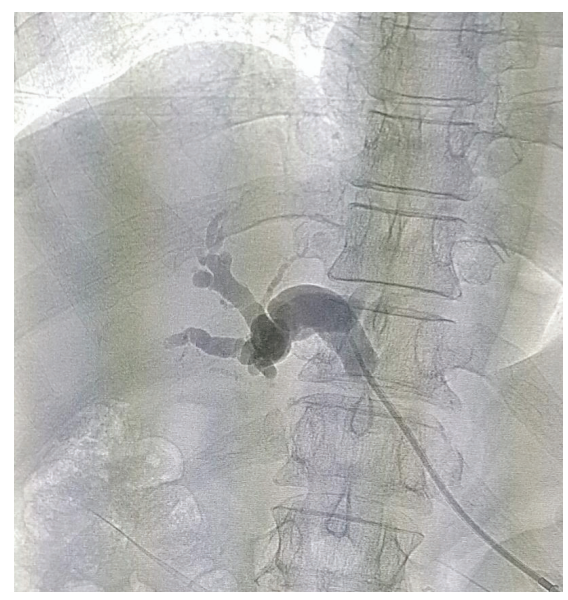

Figure 2: Cholangiogram via the left duct showing the non-visualization of right duct 
He was on regular follow up and on his $50^{\text {th }}$ day of followup at the OPD, he was able to ambulate with support and take a normal diet. His wound had healed and the drain showed $1300 \mathrm{ml}$ of serous fluid which was gradually decreasing with time. His bilirubin level and platelets count were also in the normal range.

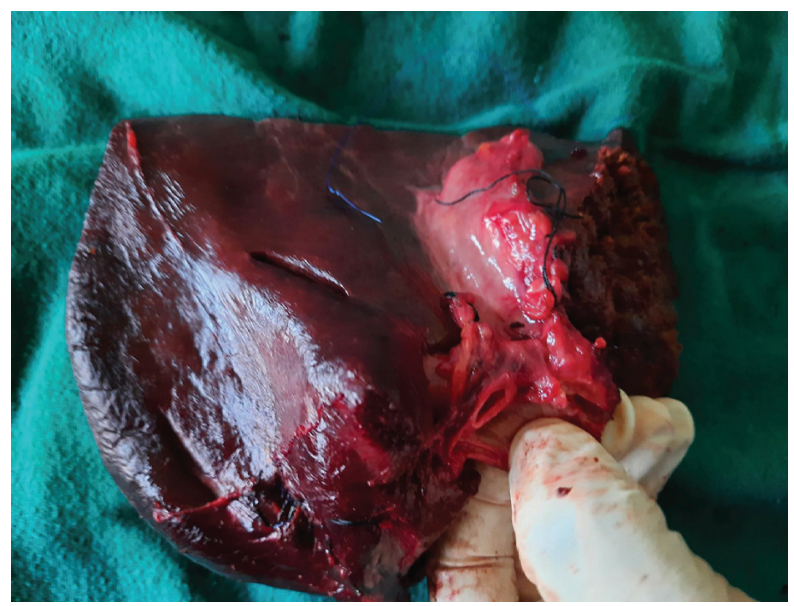

Figure 3: Final resected specimen

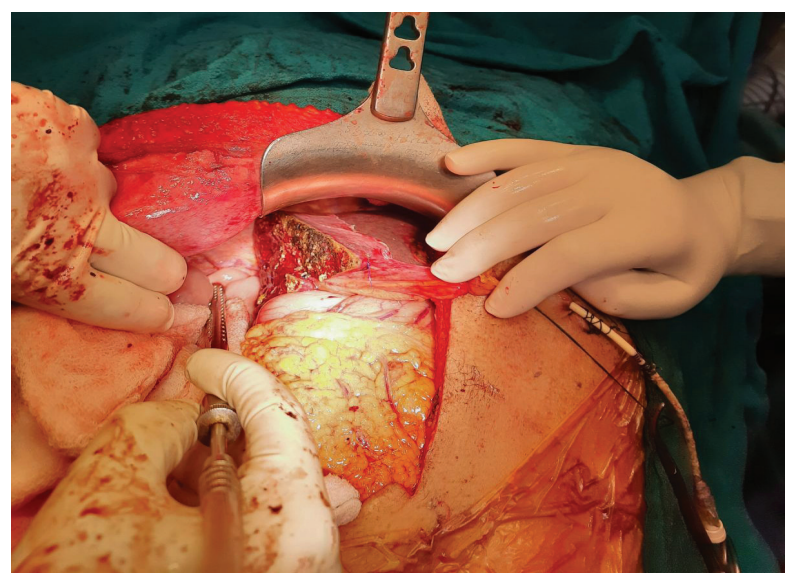

Figure 4: Resected margin of liver

\section{DISCUSSION}

Cholangiocarcinoma (CCA) is a group of rare aggressive intra and extra hepatic malignancy of the bile duct. They often present with locally advanced or metastatic disease ${ }^{6}$. The 7 th and the $8^{\text {th }}$ edition of the American Joint Committee on Cancer (AJCC) staging system, have now separated extrahepatic cholangiocarcinoma into perihilar (proximal) and distal cholangiocarcinoma based on the differences in their biological behavior, management and the prognosis. ${ }^{7}$. Therefore, there are three anatomical types of CCA: intrahepatic cholangiocarcinoma (iCCA), perihilar cholangiocarcinoma (pCCA) and distal cholangiocarcinoma $(\mathrm{dCCA})^{6}$.

Peri-hilar cholangiocarcinoma (pCCA) or hilar cholangiocarcinoma (hCCA) is the most common among the CCA, ranging from $60-70 \%{ }^{1}$. pCCA are those cholangiocarcinoma that involve or are near the biliary confluence of the right and left hepatic duct and are located proximally to the area between the secondary branch of bile ducts and distal to the insertion of the cystic duct into the common bile duct ${ }^{4}$. Proximal and distal are explained according to the direction of bile flow. The patient had a tumor in the hilum that was extending to the right hepatic duct. So this was a type Illa hilar cholangiocarcinoma.

These patients usually present with symptoms of jaundice, weight loss and abdominal discomfort. Radiological diagnosis is done mainly by contrastenhanced computed tomography (CE-CT) and contrastenhanced magnetic resonance imaging (CE-MRI). We diagnosed the case with the help of clinical symptoms and CE-CT. We did a cholangiogram via PTBD catheter to delineate the biliary anatomy and intrabiliary tumor extent.

Radical surgery provides the only curative option for hCCA, with a 5-year survival rate ranging from 9 to $41 \%$ ${ }^{8}$. Surgical treatment is thus the preferred option, with appropriate consideration for the involvement of the vascular structures and lymph nodes 9 .

However, the resectability rate of these tumor is low as they usually have a silent evolution and the patients present late. The low resectability of hilar cholangiocarcinoma is thus due to the advance nature of the disease at presentation. The deep tumor location, close proximity to the major hepatic vessels makes it cumbersome and at times very difficult to achieve free distal margin with RO resections. Cholangiocarcinoma is associated with its high desmoplastic reactions and has a rich tumor microenvironment, all these tumor characteristics contribute to its therapeutic resistance ${ }^{4}$. The proximity to the liver parenchyma in addition to the involvement of hepatic vessels often warrants the complex hepatic resections along with bile duct excision. Therefore, extended resections, including right trisegmentectomies, result in the highest rate of R0 resection ${ }^{10}$. Right trisectionectomy was done in our case to achieve the R0 resection. Mobilization could be done without much difficulty. Liver transaction was done with the help of harmonics and crush-clamp technique. Due to desmoplastic reaction, hilar dissection was difficult. 
However we could achieve the left proximal margin and anastomose the left duct with a roux-en- $y$ limb of jejunum.

In cases of liver resections, apart from R0 resections, we must make sure that the future liver remnant (FLR) volume is adequate. Due to inadequate FLR, many patients require liver augmentation technique like PVE by means of which resectability can be improved. At the same time, major hepatectomies in these cases are still associated with high rates of morbidity and mortality, nearly being $40 \%$ and $10 \%$ respectively despite improvement in the surgical technique and postoperative care ${ }^{9}$. Due to all these reasons, excision of hilar cholangiocarcinomas requires a HepatoPancreatoBiliary (HPB) surgeon trained in the respective field to carry out the surgery. Preoperative accurate staging which is crucial in clinical decision-making helped us in choosing the surgery required to achieve the Ro resection. After liver volumes calculation, PTBD and PVE was done with the help of IR team available at our centre and resection of the hCCA could finally be done in our patient with good results.

\section{REFERENCES}

1. Esnaola NF, Meyer JE, Karachristos A, Maranki JL, Camp ER, Denlinger CS. Evaluation and management of intrahepatic and extrahepatic cholangiocarcinoma: Management of Cholangiocarcinoma. Cancer. 2016 May 1;122(9):1349-69. [PubMed]

2. Jarnagin $W R$, Fong $Y$, DeMatteo RP, Gonen M, Burke EC, Bodniewicz BS J, et al. Staging, resectability, and outcome in 225 patients with hilar cholangiocarcinoma. Ann Surg. 2001 Oct;234(4):50717. [PubMed]

3. Cannon RM, Brock G, Buell JF. Surgical resection for hilar cholangiocarcinoma: experience improves resectability. HPB. 2012 Feb;14(2):142-9. [DOI]

4. Razumilava N, Gores GJ. Cholangiocarcinoma. The Lancet. 2014 Jun;383(9935):2168-79. [PubMed]

5. Shindoh J, Truty MJ, Aloia TA, Curley SA, Zimmitti G, Huang $S Y$, et al. Kinetic growth rate after portal vein embolization predicts posthepatectomy outcomes: toward zero liver-related mortality in patients with colorectal liver metastases and small future liver remnant. J Am Coll Surg. 2013 Feb;216(2):201-9. [PubMed]
The patient developed PHLF in the postoperative period. PHLF is a possible complication of major hepatic resections which can occur in up to $10 \%$ of the patients who undergo major liver resections ${ }^{11}$.As the patient could be managed with fresh frozen plasma and albumin without any invasive treatment, it was a Grade B PHLF.

Although complex, extended hepatectomies can be done safely in hilar cholangiocarcinoma with good outcome by trained surgeons with the help of a multidisciplinary team.

\section{CONCLUSION}

Resection rate for hilar cholangiocarcinoma is low because of the advanced nature of the disease at presentation. Resectability may be improved by volume augmentation as with PVE. The resection of hilar cholangiocarcinoma is a complex surgery but holistic care by trained surgeons and team can produce good results.

\section{Conflict of interest: None Source(s) of support: None}

6. Forner A, Vidili G, Rengo M, Bujanda L, Ponz-Sarvisé M, Lamarca A. Clinical presentation, diagnosis and staging of cholangiocarcinoma. Liver Int. 2019 May;39(S1):98-107. [PubMed]

7. Edge SB, Compton CC. The American Joint Committee on Cancer: the 7th Edition of the AJCC Cancer Staging Manual and the Future of TNM. Ann Surg Oncol. 2010 Jun;17(6):1471-4. [PubMed]

8. Van der Gaag NA, Kloek JJ, de Bakker JK, Musters B, Geskus RB, Busch ORC, et al. Survival analysis and prognostic nomogram for patients undergoing resection of extrahepatic cholangiocarcinoma. Ann Oncol. 2012 Oct;23(10):2642-9. [DOI]

9. Scurtu RR, Dindelegan G, Bintintan V, Drasovean R, Apostu R, Ciuce C. Extension of Hepatic Resection Ameliorates Survival in Patients with Type Illa or Illb Klatskin Tumors Despite Surgical Complications. Chirurgia (Bucur). 2017;112(3):301. [PubMed]

10. Neuhaus $P$, Jonas $S$, Bechstein WO, Lohmann R, Radke C, Kling N, et al. Extended resections for hilar cholangiocarcinoma. Ann Surg. 1999 Dec;230(6):80818. [PubMed]

11. Kauffmann R, Fong Y. Post-hepatectomy liver failure. Hepatobiliary Surg Nutr. 2014 Oct;3(5):238-46. [PubMed] 